\title{
Comparison of ammonia emissions from animal wastes and chemical fertilizers after application in the soil
}

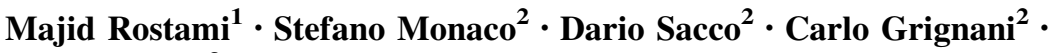 \\ Elio Dinuccio ${ }^{3}$
}

Received: 7 February 2014/ Accepted: 7 April 2015/Published online: 29 April 2015

(c) The Author(s) 2015. This article is published with open access at Springerlink.com

\begin{abstract}
Background Application of different chemical fertilizers and manures is a major source of ammonia $\left(\mathrm{NH}_{3}\right)$ emission. The rate and total amount of $\mathrm{NH}_{3}$ emission are related to different parameters such as climatic conditions, soil characteristics and kind of fertilizer. The current study has indicated the $\mathrm{NH}_{3}$ emission from bovine slurry, pig slurry and ammonium nitrate fertilizer after application on two soils. Two different methods were used to measure $\mathrm{NH}_{3}$ emissions: the method that use acid traps and the method that use photoacoustic infrared gas analyzer.

Results In both soils the rate of $\mathrm{NH}_{3}$ emission was the greatest from the denser bovine slurry, declined in the pig slurry followed by the ammonium nitrate treatment and the
\end{abstract}

Majid Rostami

Majidrostami7@yahoo.com

Stefano Monaco

Stefano.Monaco@unito.it

Dario Sacco

Dario.Sacco@unito.it

Carlo Grignani

Carlo.Grignani@unito.it

Elio Dinuccio

Elio.Dinuccio@unito.it

1 Department of Agronomy, University of Malayer, 657719-95863 Malayer, Iran

2 Department of Agricultural, Forest and Food Sciences, University of Turin, L.go Braccini 2, 10095 Grugliasco, Italy

3 Mechanics Section, Department of Agricultural, Forest and Food Sciences, University of Turin, L.go Braccini 2, 10095 Grugliasco, Italy control. The rate of soil infiltration could be the main factor that explained these differences. For all treatments the amount of total $\mathrm{NH}_{3}$ losses reduced in the more acidic soil. For all fertilizers the highest $\mathrm{NH}_{3}$ fluxes were measured in the first hours after spreading. A good agreement observed between the two methods is used for determining of $\mathrm{NH}_{3}$ emission. The use of a multi-gas monitor (MGM) is simple and accurate and produces a continuous series of $\mathrm{NH}_{3}$ concentration in time.

Conclusion The rate and amount of $\mathrm{NH}_{3}$ emission was related to the kind of fertilizers and interaction of these treatments with soils. The results of current study confirmed that comparison of chemical fertilizers and slurry for $\mathrm{NH}_{3}$ emission is difficult because the reaction of these two groups of fertilizer is totally different.

Keywords Ammonia emission - Laboratory methods · Mineral fertilizer · Slurry

\section{Introduction}

Ammonia $\left(\mathrm{NH}_{3}\right)$ may be released into the atmosphere from basically all ammonium-containing products. Livestock and especially animal manures are the most important sources of $\mathrm{NH}_{3}$ emissions in Europe, followed by the application of mineral nitrogen fertilizers (Leip et al. 2011). The increase in animal stocking and in the price of chemical fertilizers encourage farmers to use animal manure and slurry as an option to reduce the use of commercial fertilizers. However, the handling and spreading of these fertilizers may pose an agronomic and environmental risk, not only because of leakage of nitrate to ground waters but also because of gaseous losses of $\mathrm{NH}_{3}$ (Asman 1992). Ammonia can form secondary particulate matter in the 
atmosphere that may have adverse effects on human health (Moldanová et al. 2011).

Ammonia emissions from manure applied to the soil are produced primarily by physical and chemical processes and secondarily by biological ones (Monaco et al. 2012). Ammonia losses from manure are harmful from the agronomic point of view, because they decrease the amount of manure $\mathrm{N}$ available for the crop (Smil 1999). Olivier et al. (1998) estimated that about $70 \%$ of global $\mathrm{NH}_{3}$ emission is related to food production and, in particular, to manure management.

A comprehensive understanding of the post application fate of fertilizers is essential for the development of best management practices that aim to minimize off-site transport and maximize nutrient use efficiency. Different variables affect both the rate and extent of emissions following soil application of manures (Meisinger et al. 2001). The dominant factors influencing losses can be categorized as: manure characteristics (dry matter content, $\mathrm{pH}, \mathrm{NH}_{4}-\mathrm{N}$ content), application methods (incorporation, time of application), soil properties (soil moisture, soil texture, soil $\mathrm{pH}$ ), and environmental factors (temperature, wind speed, rainfall, relative humidity).

A number of techniques have been developed to quantify $\mathrm{NH}_{3}$ emission. Accuracy and mechanism of these methods are very different. Such techniques fall generally in two groups: micro-meteorological methods (usually used for large scale areas) and enclosure methods (commonly used on small plots for comparative experiments). Chamber methods that belong to second category are usually used for measuring emission at the small scale both in the field and in the laboratory. Three measurement schemes are commonly used for the chamber methods: the open chamber, the closed static chamber and the closed dynamic chamber. All methods employ an inverted chamber covering a small area of soil. The lower edge of the chamber usually is inserted into the soil to a shallow depth.

The analysis of $\mathrm{NH}_{3}$ emission have been carried out using different methods as acid traps or direct measurement through a multi-gas monitor (MGM). Between them, using MGM is easier because this system provides a real-time analysis of $\mathrm{NH}_{3}$ concentration (Dinuccio et al. 2008). Experiments for measuring $\mathrm{NH}_{3}$ emissions are usually carried out in the field where soil and moisture conditions and other environmental factors are variable and hard to control. Unfortunately, little effort has been made to standardize the laboratory methods for $\mathrm{NH}_{3}$ emission measurement. The objectives of this experiment were to measure $\mathrm{NH}_{3}$ emissions from different slurries using closed dynamic chambers with both acid traps and MGM method under controlled environmental conditions and assessing the influence of two different soils on modifying $\mathrm{NH}_{3}$ emissions.

\section{Materials and methods}

The amount of volatilized $\mathrm{NH}_{3}$ after surface application of different fertilizers in two soil types was assessed under constant and controlled environmental conditions using dynamic chamber technique (Roelle and Aneja 2002). The soils used in the experiment presented different physical and chemical characteristic (Table 1) and were representatives of arable soil types of the western Po river plain (Northern Italy). In particular, Poirino soil came from a farm field cultivated mainly with maize for grain in rotation with wheat receiving chemical fertilizations, while Tetto Frati soil (TF) was collected from an experimental field continuously cultivated with maize for grain fertilized with cattle slurry and urea. The soil samples were collected from the tilled top $20 \mathrm{~cm}$ layer on, air-dried and sieved using $2 \mathrm{~mm}$. Cylindrical glass jars (3.1 1) were filled with 1.11 of each soil type moistened to reach the field capacity (FC). In particular, 1595 and $1475 \mathrm{~g}$ of dry soil was moistened with 367 and $428 \mathrm{ml}$ of deionized water for Poirino and TF soil, respectively. Soil moisture content at FC $(-33 \mathrm{kPa})$ was measured on 4 replicates for each soil type using pressure plates and was equal to 0.23 and $0.29 \mathrm{~g}$ of $\mathrm{H}_{2} \mathrm{O}$ per $\mathrm{g}$ of dry soil for Poirino and TF, respectively. Bulk density of soils at FC were measured by drying $100 \mathrm{~cm}^{3}$ of soil (four replicates) at $105{ }^{\circ} \mathrm{C}$ for 3 days, and were equal to 1.45 and $1.34 \mathrm{~g}$ of dry soil per $\mathrm{cm}^{3}$.

Organic fertilizers used in the experiment were pig slurry (PS) and bovine slurry (BS). Slurries were collected from storage facilities of two farms few days before the beginning of experiment, stored at $4{ }^{\circ} \mathrm{C}$ and analyzed for the main characteristics (Table 2). Fertilizers were applied at a rate of $85 \mathrm{~kg} \mathrm{ha}^{-1}$ of total N. In particular, 34.8 and $67.4 \mathrm{~g}$ of PS and BS were gently distributed on the surface of the jars $\left(154 \mathrm{~cm}^{2}\right)$, providing $131 \mathrm{mg} \mathrm{jar}^{-1}$ of total $\mathrm{N}$ and 95 and $65 \mathrm{mg} \mathrm{jar}^{-1}$ of ammoniacal $\mathrm{N}$ for PS and BS, respectively. For each soil type, a treatment fertilized with ammonium nitrate at the rate of $85 \mathrm{~kg} \mathrm{ha}^{-1}$ of total $\mathrm{N}$ was also prepared. Ammonium nitrate was solubilised in $15 \mathrm{ml}$ deionized water and distributed on the soil surface. In addition, one extra jar in which BS was
Table 1 Physical and chemical properties of soils

\begin{tabular}{lllllllll}
\hline Soil & Sand $(\%)$ & Silt $(\%)$ & Clay $(\%)$ & CEC Meq/100 g & $\mathrm{pH}$ & $\mathrm{OM}(\%)$ & $\mathrm{N}(\%)$ & $\mathrm{C} / \mathrm{N}$ ratio \\
\hline Poirino & 15.8 & 75.5 & 8.7 & 16.7 & 6.2 & 2.4 & 0.14 & 9.6 \\
TF & 48.4 & 43.1 & 8.5 & 12.4 & 7.9 & 2 & 0.17 & 7 \\
\hline
\end{tabular}


Table 2 Physical and chemical properties of the slurries

\begin{tabular}{lllll}
\hline Slurry type & Dry matter $(\%)$ & $\mathrm{pH}$ & $\mathrm{N}(\%)$ & TAN (\%) \\
\hline Bovine & 5.8 & 8.5 & 19 & 10 \\
Pig & 2.3 & 8.0 & 38 & 27 \\
\hline
\end{tabular}

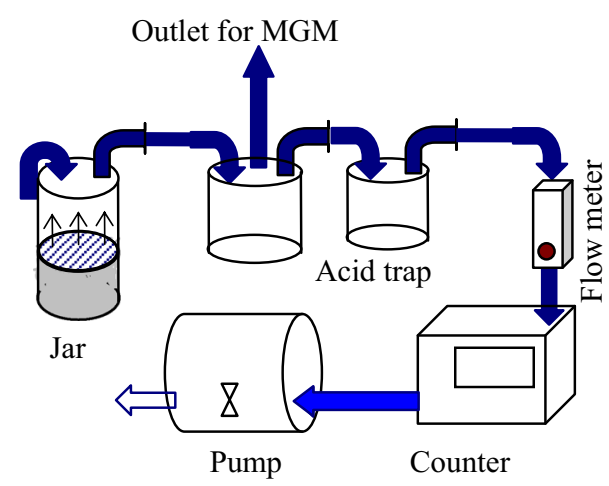

Fig. 1 Schematic diagram of the measuring system

incorporated in Poirino soil was also analyzed. For each soil type, an unfertilized soil was used as control treatment. One replication for each treatment was measured in three different sessions of measurement in a growth chamber properly equipped for $\mathrm{NH}_{3}$ emission assessment using open dynamic chamber method. Each session was conducted at $25{ }^{\circ} \mathrm{C}$ under controlled environmental conditions. Ammonia concentration in the incoming air (background) was always measured and found negligible (0.08 ppm).

Immediately after fertilization, jars were closed with airtight lids prepared with one input and one output port directing air into the headspace and connecting the jars to the measurement system (Fig. 1). In particular, each jar was connected first to an expansion bottle and then connected in an air-tight way with a Drechsel bottle, flow meter, gas meter and pump. The flow rate $\left(21 \mathrm{~min}^{-1}\right)$ was chosen to ensure a minimal exchange rate, but also to prevent rapid drying of the soil surface. It corresponded to an air renewal rate of one headspace volumes $\min ^{-1}$ with an average air flow rate of $0.12 \mathrm{~m}^{3} \mathrm{~h}^{-1}$. The air flow rate was monitored over each jar using one volumetric air flow meter per jar. From the expansion bottles another outlet tube was inserted for measuring of $\mathrm{NH}_{3}$ concentration using photoacoustic infrared gas analyzer (Innova 1412).

In the acid trap method, the air stream passing through the jar and the expansion bottle arrived to a $\mathrm{NH}_{3}$ scrubber containing $100 \mathrm{ml}$ of $0.1 \mathrm{~N} \mathrm{H}_{2} \mathrm{SO}_{4}$, in which absorbed $\mathrm{NH}_{3}$ was converted to ammonium sulfate. All of the acid samples were stored at $4{ }^{\circ} \mathrm{C}$ until the analysis. The amount of $\mathrm{NH}_{3}$ absorbed in each scrubber was determined using an ionometer (Ion lab, WTW). The $\mathrm{NH}_{3}-\mathrm{N}$ concentration in the outgoing air was calculated from the data of ionometer multiplied by the volume of acid trap.

Measurements with acid traps were carried out in four intervals of $5 \mathrm{~h}$ during the first 4 days after slurry application. Measuring for 4 days was considered enough to reveal the possible differences in $\mathrm{NH}_{3}$ emission, because according to earlier studies $\mathrm{NH}_{3}$ emission is at its highest rate on the day of application and declines sharply in the following few days (Yang et al. 2003). The total amount of emitted $\mathrm{NH}_{3}$ during the 4 days was derived by interpolation of the integral form of a power curve of the amount of $\mathrm{NH}_{3}$ trapped in the Drechsel bottle during the four measurements.

Simultaneously, measurements with MGM were carried out during the first 2 days after fertilization, when the $\mathrm{NH}_{3}$ emissions were expected to be high for fertilized treatments. Gas sample suction for MGM started approximately 30 min after the closing of chamber to allow stabilization of $\mathrm{NH}_{3}$ concentration in the expansion bottle and was repeated three times for treatment during each interval of measurement. Before each measurement, Teflon tubes connecting the system to MGM were cleaned with background air flush.

The $\mathrm{NH}_{3}$ readings by MGM (mg/l) were multiplied by a correction factor for the atmospheric pressure. $\mathrm{NH}_{3}$ concentrations $(\mathrm{mg} / \mathrm{l})$ were converted into the flux of $\mathrm{NH}_{3}$ leaving each jar as follows:

$\mathrm{FNg}=$ air volume $\times \mid$ conc $\mid \times 10^{-6} \times \rho \mathrm{NH}_{3} \times(14 / 17)$

where $\mathrm{FNg}$ is the $\mathrm{NH}_{3}-\mathrm{N}$ flux in mg N per jar; air volume is the throughput of air during one measurement; lconcl is the value of the corrected volume concentration (vol. $\mathrm{mg} / \mathrm{l}$ ) of $\mathrm{NH}_{3} ; \quad \mathrm{NNH}_{3}$ is the density of $\mathrm{NH}_{3}$ in $\mathrm{mg} \mathrm{l}^{-1}$ $\left(\rho \mathrm{NH}_{3}=696 \mathrm{mg} \mathrm{l}^{-1} ; 25{ }^{\circ} \mathrm{C}, 1013 \mathrm{hPa}\right)$.

The total amount of $\mathrm{NH}_{3}$ emitted during each interval of measurement was calculated separately for each treatment by the integration on time basis of the measurements carried out with MGM, using linear, exponential and power function. The results were then compared with total amount of $\mathrm{NH}_{3}$ emitted as measured with acid traps. Calculations and drawing the trend lines was done with using Microsoft Excel-2003, and SPSS.

\section{Results}

\section{Comparison of manures using the acid trap method}

Immediately after the application of fertilizers, $\mathrm{NH}_{3}$ emission started and continued up to the end of the experiment. Based on Kruskal-Wallis test $(P \leq 0.05)$ differences among treatments were significant. Until the third day of experiment, the ranking of treatments did not change and the rate of $\mathrm{NH}_{3}$ emissions were highest in $\mathrm{BS}$, 
followed by PS and ammonium nitrate, and were very low in control for both soils. Incorporation of BS strongly reduced emission to the level of control treatment. On day 4 the ranking of the treatments was different, but emissions were very low (Fig. 2).

One day after application of fertilizers, $\mathrm{NH}_{3}$ fluxes declined sharply by about sevenfold in slurry treatments and threefold in mineral fertilizer (Fig. 2). Ammonia fluxes had fallen to the lowest levels by the third or fourth day depending on the treatments. Based on results the most $\mathrm{NH}_{3}$ losses occurred during the first day after application of fertilizer.

With respect to their $\mathrm{NH}_{3}$ emissions both the slurry treatments showed systematic time course patterns over the 4 days. The soils fertilized with pure mineral fertilizer, also showed similar patterns, but at much lower levels. The emission rate did not change in time from the manure incorporated treatment and the control treatment, that showed a low and steady flux during the whole experiment.
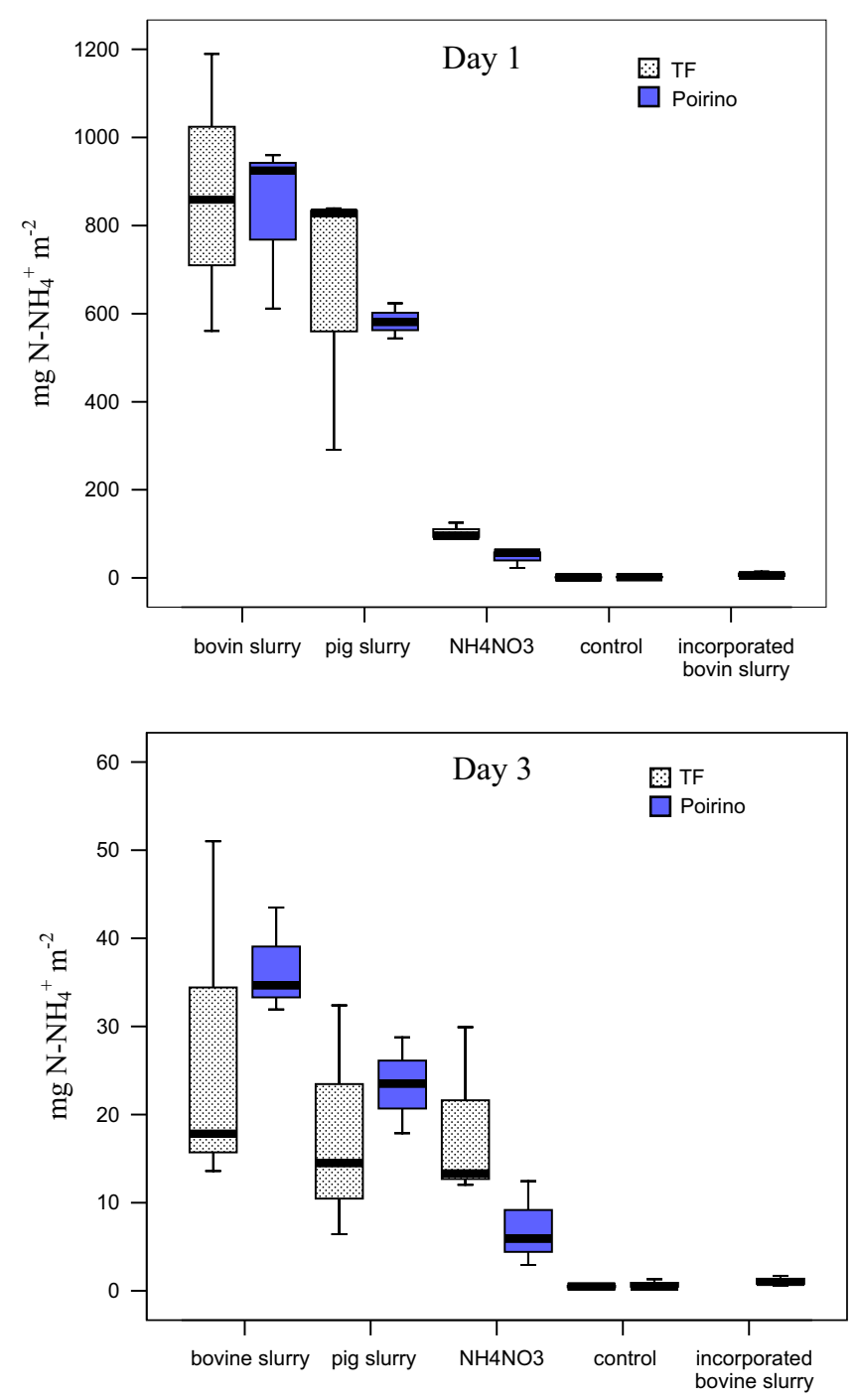

The total emissions of $\mathrm{NH}_{3}$ during the experimental period were calculated using integral of measured emission rate with acid trap method (Fig. 3a) and reported as a percentage of ammoniacal nitrogen applied (Fig. 3b). In both the cases Kruskal-Wallis test reported significant differences among treatments.

The rate and total amount of $\mathrm{NH}_{3}$ emission was related to kind of fertilizers. In this experiment the range of $\mathrm{NH}_{3}$ emission from BS was 39-82 \% of total ammoniacal nitrogen (TAN) applied and the amount of emitted $\mathrm{NH}_{3}$ in PS and ammonium nitrate varied from $13-38$ to $2-18 \%$ of TAN, respectively. This shows that the higher dry matter content of the slurry the higher emission rate.

Figure 3 shows that there was a similar ranking of treatments for total amount of emitted $\mathrm{NH}_{3}$ and of the ratio between emitted $\mathrm{NH}_{3}$ and TAN. In other words, in our experiment the amount of TAN in the different fertilizers did not affect the final $\mathrm{NH}_{3}$ emissions. The amount of total
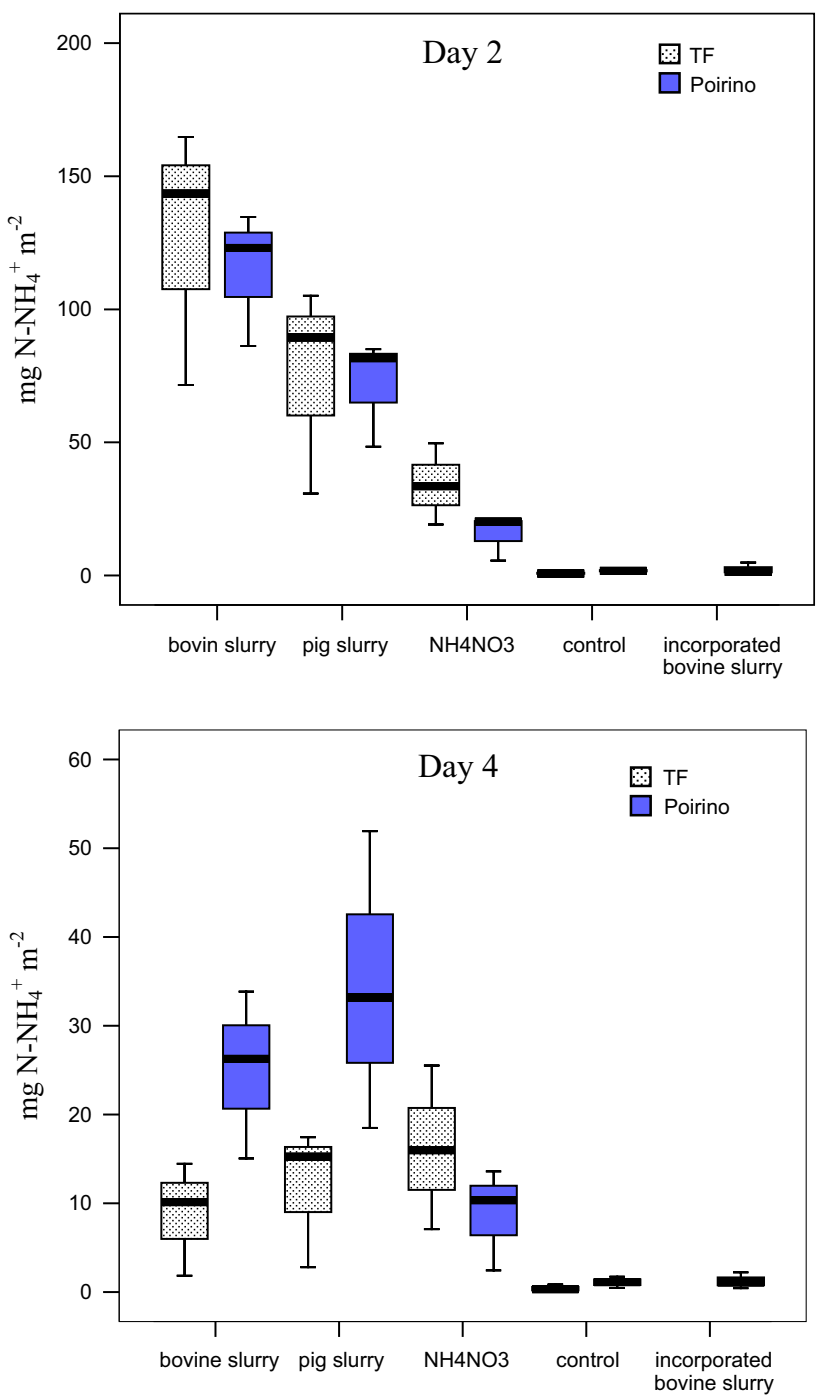

Fig. 2 Ammonia emission from different treatments during measurement times in each day (measured with acid traps) 

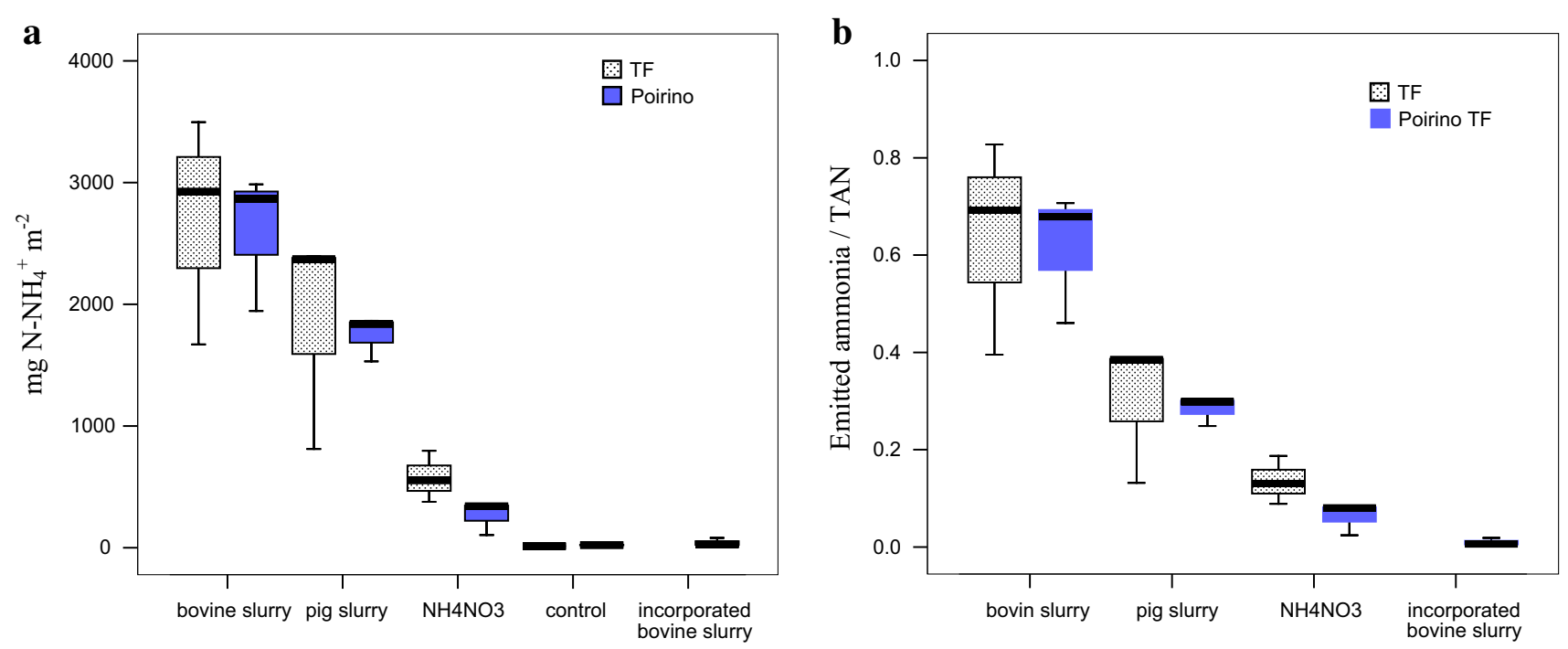

Fig. 3 Total amount of emitted ammonia from different treatments during the experiment (a), and ratio between emitted ammonia and total ammoniacal nitrogen (TAN) in different treatments (b) (measured with acid traps)

$\mathrm{NH}_{3}$ losses in the calcareous TF soil was higher than in the more acidic Poirino soil for PS and ammonium nitrate treatment, the two fertilizers that are expected to better infiltrate into soil because of lower dry matter. Instead no differences observed for the BS, which was the fertilizer characterized by higher dry matter.

\section{Comparison of the two methods for ammonia measurements}

Using MGM the highest $\mathrm{NH}_{3}$ fluxes were measured during the first hour following the application of fertilizer in all the fertilized treatments (Fig. 4). But it is likely that the fluxes immediately after application were still greater, due to the delay (about $30 \mathrm{~min}$ ) in the beginning of measurements. The time variation patterns of $\mathrm{NH}_{3}$ concentration in the air fluxes were similar in both the methods. In the second day after application of fertilizers, $\mathrm{NH}_{3}$ fluxes declined sharply by about sixfold in slurry treatments and less than twofold in mineral fertilizer (Fig. 4).

For the interpolation of the amount of emitted $\mathrm{NH}_{3}$ measured with MGM in each interval, three different mathematical models were used. A strong linear relationship was observed between the $\mathrm{NH}_{3}$ concentration by acid trap and MGM methods (Fig. 5), but in general, the amount of emitted $\mathrm{NH}_{3}$ measured with MGM was higher than that measured by acid trap. Comparison of the three methods used for calculation of the total amount of emission showed that they are all acceptable, but the best method for representing data of MGM in short times (5 h) is using the
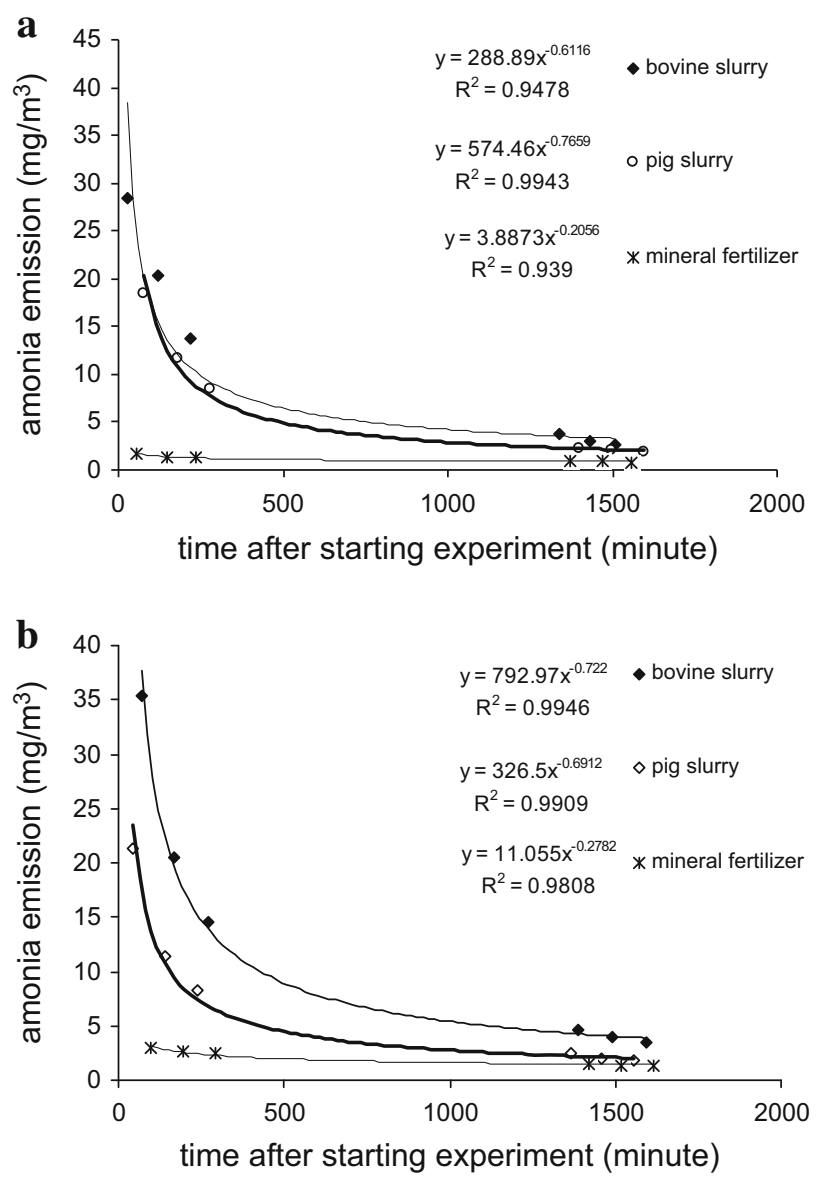

Fig. 4 Rate of ammonia emission measured with MGM in a Poirino and $\mathbf{b}$ TF soil 

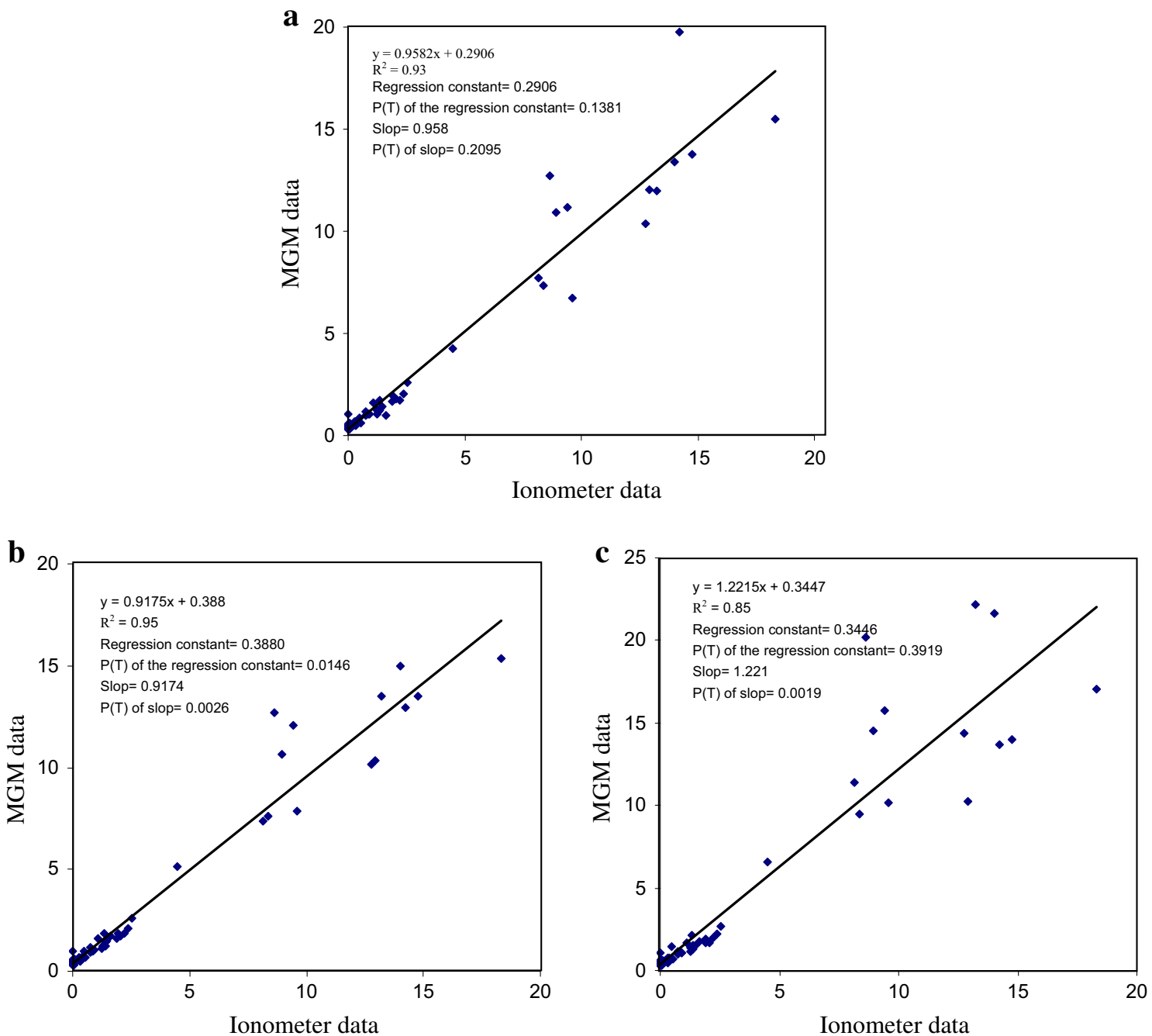

Fig. 5 Regression between amounts of ammonia emission measured by ionometer and derived from MGM measurements interpolated with $\mathbf{a}$ linear, $\mathbf{b}$ exponential and $\mathbf{c}$ power function

linear function, whereas the use of a linear function for representing the trend of $\mathrm{NH}_{3}$ emission in longer duration (day) is not justified.

\section{Discussion}

The highest rate of $\mathrm{NH}_{3}$ fluxes was measured using MGM in the first day and in the second day after application of fertilizers $\mathrm{NH}_{3}$ fluxes declined sharply. Huijsmans et al. (2001) reported that the rate of $\mathrm{NH}_{3}$ emission decreased with time. $\mathrm{NH}_{3}$ emission also decreases with a reduction in slurry water content because the water content initially decreases due to infiltration of the slurry liquid into the soil.

Meisinger et al. (2001) reported that losses of $\mathrm{NH}_{3}$ through emission are very rapid during the first 6-12 $\mathrm{h}$ after application. Results of previous study showed that 30-70\% of the total $\mathrm{NH}_{3}$ loss from cattle slurry occurred in the first 4-6 h, and 50-90\% in the first day (Stevens and Laughlin 1997); however, this result was related to the application of slurries in grassland and is not totally comparable with our results obtained under controlled conditions.

The TAN concentration of pig slurry was higher and the dry matter content was lower than that of the bovine slurry, as it is often the case (Dinuccio et al. 2008), but in this experiment the higher amount of $\mathrm{NH}_{3}$ emission was observed when BS was applied. This result is probably related to interaction between soil and slurry.

Higher dry matter content of the bovine slurry decreased infiltration into the soil, and it increased the chances of $\mathrm{NH}_{3}$ losses, as it was also indicated by Stevens et al. (1992). The slurry dry matter content has been shown to be an important factor in determining the $\mathrm{NH}_{3}$ emission potential. Sommer and Olesen (2000) showed a linear relationship between 
cattle slurry dry matter content and $\mathrm{NH}_{3}$ emission in the range 4-12\% DM, but outside this range dry matter had a little effect on $\mathrm{NH}_{3}$ emission. Smith et al. (2000) reported a similar linear relationship but in a shorter range $(2-5 \%$ of slurry dry matter) and concluded that for every $1 \%$ increase in slurry dry matter, $\mathrm{NH}_{3}$ losses increased about $6 \%$. In the MANNER model that was developed for predicting $\mathrm{NH}_{3}$ emission from manure, it was suggested that for every $1 \%$ increase in manure $\mathrm{DM}, \mathrm{NH}_{3}$ loss increases about $5 \%$ (Chambers et al. 1999). In the Poirino soil the difference between total amount of emitted $\mathrm{NH}_{3}$ from BS and PS was higher than in TF soil (Fig. 2), and this difference probably was related to the soil texture because the importance of slurry dry matter (for $\mathrm{NH}_{3}$ emission) in soils with a poor infiltration rate is higher (Jarvis and Pain 1990).

Soil $\mathrm{pH}$ and cation exchange capacity (CEC) also influenced $\mathrm{NH}_{3}$ emission. When the fertilizer could infiltrate in the soil, the higher $\mathrm{pH}$ of the TF soil enhanced $\mathrm{NH}_{3}$ emission in comparison with the soil of Poirino. This confirms that lower $\mathrm{pH}$ leads to a lower proportion of aqueous $\mathrm{NH}_{3}$ and therefore decreases $\mathrm{NH}_{3}$ emission ( $\mathrm{Li}$ 2000). Huijsmans et al. (2003) and FAO (2001) reported similar results, in which the increase of $\mathrm{pH}$ and decrease of CEC could raise $\mathrm{NH}_{3}$ emission of 10 times. Soil surface $\mathrm{pH}$ greatly changes when slurry is applied to soil, due to the different buffering capacities of the soil and slurry. The highest reaction of $\mathrm{NH}_{3}$ emission to $\mathrm{pH}$ was observed when $\mathrm{pH}$ ranges from 7 to 10 , and $\mathrm{NH}_{3}$ emission below 7 decreases dramatically (Hartung and Phillips 1994). Using a mechanistic model for estimating the $\mathrm{NH}_{3}$ emission from slurry after application in soil Genermont and Cellier (1997) $\mathrm{pH}$ was the main factor that influenced $\mathrm{NH}_{3}$ emission. They reported that the reduction of the $\mathrm{pH}$ from 7 to 6 resulted in $19 \%$ decrease of $\mathrm{NH}_{3}$ emission.

The total amount of emitted $\mathrm{NH}_{3}$ measured in our experiment was close to the values reported in other experiments. Stevense and Laughlin (1997) showed that $\mathrm{NH}_{3}$ losses from surface applied liquid cattle manure in grassland was in the range 40-70\%, whereas $\mathrm{NH}_{3}$ losses from poultry litter in pasture ranged from 28 to $46 \%$ of TAN (Marshall et al. 1998).

This research work confirmed the general idea that the amount of emitted $\mathrm{NH}_{3}$ from mineral fertilizer is less than from slurry. Whitehead and Raistrick (1990) estimated that only $3.4 \%$ of the applied $\mathrm{N}$ in chemical fertilizer (five nitrogen compounds) was lost as $\mathrm{NH}_{3}$. In reporting emissions from fertilizers for the UK, Lee and Dollard (1994) used emission factors of $3 \%$ for ammonium nitrate.

Incorporation of slurry almost suppressed $\mathrm{NH}_{3}$ emission and in this treatment total amount of emitted $\mathrm{NH}_{3}$ was negligible. Other researchers also mentioned that incorporation of manure was one of the best methods for decreasing $\mathrm{NH}_{3}$ emission. Rodhe et al. (2006) reported that by injection of slurry into the soil the emission decreased by $39 \%$ in comparison with the band spreading of slurry. By incorporating and mixing slurries with soil, contact area between the slurry and the air was reduced, and therefore $\mathrm{NH}_{3}$ emission in comparison with surface application was decreased. Sommer et al. (1991) reported that evaporation of water from the manure lead to an increase of the aqueous $\mathrm{NH}_{3}$ concentration in the manure and to an increase in $\mathrm{NH}_{3}$ emission.

Results of this experiment showed that for calculating total amount of emitted $\mathrm{NH}_{3}$ by MGM, different functions should be used because the trend of $\mathrm{NH}_{3}$ emission based on the time scale of measurement is different. Regarding the $\mathrm{NH}_{3}$ emission rate measured with MGM in the first 2 days, power function can represent the data in better comparison to linear functions. These results are in agreement with results of other experiment (Bussink et al. 1996) that showed that the trend of $\mathrm{NH}_{3}$ emission rate from applied manure was not linear. The results of this experiment are also in contrast with results from Chambers et al. (1997), who observed linear rates of emission from poultry litter for up to 3 weeks after application.

\section{Conclusion}

The rate and amount of $\mathrm{NH}_{3}$ emission were related to the kind of fertilizers and interaction of these treatments with soils. Comparison of chemical fertilizers and slurry for $\mathrm{NH}_{3}$ emission is difficult because the reaction of these two groups of fertilizer is totally different. The amount of emitted $\mathrm{NH}_{3}$ from different fertilizers was related to the amount of water added to the soil with the application and consequently to the infiltration of the slurry into the soil. It seems that 4 days are enough for the estimation of the $\mathrm{NH}_{3}$ emission from slurry, but longer time is needed for chemical fertilizers. The strong linear correlations between the results of the two measurement methods demonstrated that MGM was also utilizable for determination of the total amount of emitted $\mathrm{NH}_{3}$ in different treatments even though a slight overestimation existed.

Open Access This article is distributed under the terms of the Creative Commons Attribution 4.0 International License (http:// creativecommons.org/licenses/by/4.0/), which permits unrestricted use, distribution, and reproduction in any medium, provided you give appropriate credit to the original author(s) and the source, provide a link to the Creative Commons license, and indicate if changes were made.

\section{References}

Asman WAH (1992) Ammonia emission in Europe: updated emission and emission variations. RIVM, Bilthoven, $\mathrm{p} 88$

Bussink DW, Lowry A, Harper A, Corre WJ (1996) Ammonia transport in a temper- temperate grassland, 11: Diurnal 
fluctuations in response to weather and management conditions. Agron J 88:621-626

Chambers BJ, Smith K, Van der Weerden T (1997) Ammonia emissions following the land spreading of solid manures. In: Jarvis S, Pain B (eds) Gaseous nitrogen emissions from grasslands. $\mathrm{CAB}$ International, Wallingford

Chambers BJ, Lord EI, Nicholson FA, Smith KA (1999) Predicting nitrogen availability and losses following application of organic manure to arable land: MANNER. Soil Use Manag 15:137-143

Dinuccio E, Berg W, Balsari P (2008) Gaseous emissions from the storage of untreated slurries and the fractions obtained after mechanical separation. Atmos Env 42:2448-2459

FAO (2001) Global inventory of $\mathrm{NH}_{3}$ emissions from mineral fertilizers and animal manure applied to croplands and grasslands. Bouwman, Rome

Genermont S, Cellier P (1997) A mechanistic model for estimating ammonia volatilization from slurry applied to bare soil. Agric Forest Meteo 88:145-167

Hartung J, Phillips VR (1994) Control of gaseous emissions from livestock buildings and manure stores. J Agric Eng Res 57:173-189

Huijsmans JFM, Hol JMG, Hendriks MMWB (2001) Effect of application technique, manure characteristics, weather and field conditions on ammonia volatilization from manure applied to grassland. Neth J Agric Sci 49:323-342

Huijsmans JFM, Hol JMG, Vermeulen GD (2003) Effect of application method, manure characteristics, weather and field conditions on ammonia volatilization from manure applied to arable land. Atmos Env 37:3669-3680

Jarvis SC, Pain BF (1990) Ammonia volatilisation from agricultural land. In: Proceedings the fertilisers society no. 298. Greenhill House, Peterborough, p 35

Lee DS, Dollard GJ (1994) Uncertainties in current estimates of emissions of ammonia in the United Kingdom. Eviron Pollut 86:267-277

Leip A, Achermann B, Billen G, Bleeker A, Bouwman AF, de Vries W, Dragosits U, Döring U, Fernall D, Geupel M, Heldstab J, Johnes P, Le Gall AC, Monni S, Nevečeřal R, Orlandini L, Prud'homme M, Reuter HI, Simpson D, Seufert G, Spranger T, Sutton MA, van Aardenne J, Voß M, Winiwarter W (2011) In: Sutton et al. (Eds.), The European nitrogen assessment. Sources, effects and policy perspectives. Cambridge University Press, Cambridge, pp 345-376

Li CS (2000) Modeling trace gas emissions from agricultural ecosystems. Nut Cycl Agroecosys 58:259-276

Marshall SB, Wood CW, Braun LC, Cabrera ML, Mullin MD, Guertal EA (1998) Ammonia volatilization from tall fescue pastures fertilized with broiler litter. J Environ Qual 27:1125-1129

Meisinger JJ, Lefcourt AM, Thompson RB (2001) Construction and validation of small mobile wind tunnels for studying ammonia volatilization. App Eng in Agr 17:375-381

Moldanová J, Grennfelt P, Jonsson A, Simpson D, Spranger T, Aas W, Munthe J, Rabl A (2011) Nitrogen as a threat to European air quality. In: Sutton et al. (Eds.), The European nitrogen assessment. Sources, effects and policy perspectives. Cambridge University Press, Cambridge, pp 405-433

Monaco S, Sacco D, Pelissetti S, Dinuccio E, Balsari P, Rostami M, Grignani C (2012) Laboratory assessment of ammonia emission after soil application of treated and untreated manures. J Agric Sci 150:65-73

Olivier JGJ, Bouwman AF, Van der Hoek KW, Berdowski JJM (1998) Global air emission inventories for anthropogenic sources of $\mathrm{NO}_{\mathrm{x}}, \mathrm{NH}_{3}$ and $\mathrm{N}_{2} \mathrm{O}$ in 1990. Env Poll 102:135-148

Rodhe L, Pall M, Yamulki S (2006) Nitrous oxide, methane and ammonia emissions following slurry spreading on grassland. Soil Use Manag 22:229-237

Roelle PA, Aneja VP (2002) Characterization of ammonia emissions from soils in the upper coastal plain, North Carolina. Atmos Env 36:1087-1097

Smil V (1999) Nitrogen in crop production: an account of global flows. Glob Biogeochem Cyc 13:647-662

Smith KA, Jackson DR, Misselbrook TH, Pain BF, Johnson RA (2000) Reduction of ammonia emission by slurry application technique. J agric Engng Res 77:277-287

Sommer SG, Olesen JE (2000) Modelling ammonia volatilization from animal slurry applied with trail hoses to cereals. Atmos Env 34:2361-2372

Sommer SG, Olesen JE, Christensen BT (1991) Effects of temperature, wind speed and air humidity on ammonia volatilization from surface applied cattle slurry. J Agric Sci 117:91-100

Stevens RJ, Laughlin RJ (1997) The impact of cattle slurries and their management on ammonia and nitrous oxide emissions from grassland. In: Jarvis SC, Pain BF (eds) Gaseous nitrogen emissions from grasslands, CAB International, Wallingford, $\mathrm{p} 233$

Stevens RJ, Laughlin RJ, Frost JP (1992) Effects of separation, dilution, washing and acidification on ammonia volatilization from surface-applied cattle slurry. J Agric Sci 119:383-389

Whitehead DC, Raistrick N (1990) Ammonia volatilization from five nitrogen compounds used as fertilizers following surface application to soils. J Soil Sci 47:387-394

Yang Z, Nimbi H, Kanda K, Suga Y (2003) Measurment of ammonia volatilization from a field, in upland Japan, spread with cattle slurry. Env Poll 121:463467 